\title{
Storage Problem Identified
}

National Cancer Institute

\section{Source}

National Cancer Institute. Storage Problem Identified. NCI Thesaurus. Code C92119.

Problems that result from storing the device in an uncontrolled or improper environment (e.g. moisture sensitive devices stored in a humid environment). 